\title{
Measuring prehepatic insulin secretion using a population model of C-peptide kinetics: accuracy and required sampling schedule
}

\author{
R.Hovorka ${ }^{1}$, E. Koukkou ${ }^{2}$, D. Southerden ${ }^{1}$, J.K.Powrie ${ }^{2}$, M. A. Young ${ }^{3}$ \\ ${ }^{1}$ Metabolic Modelling Group, Centre for Measurement and Information in Medicine, City University, London, UK \\ ${ }^{2}$ Department of Diabetes and Endocrinology, Division of Medicine, United Medical and Dental Schools, St. Thomas' Hospital, \\ London, UK \\ ${ }^{3}$ Glaxo Wellcome Research and Development plc, Department of Pharmacokinetics, Greenford, Middlesex, UK
}

\begin{abstract}
Summary The accuracy of calculations of pre-hepatic insulin secretion were investigated, to provide independent validation of a population model of C-peptide kinetics. The effects of sampling frequency were also assessed. Five normal subjects (aged 28 to 43 years; BMI $\left(\mathrm{kg} / \mathrm{m}^{2}\right) 20.5$ to 24.5$)$ and five subjects with non-insulin-dependent diabetes mellitus (NIDDM) treated by diet alone (aged 34 to 57 years; BMI 22.6 to 25.6) were given a variable intravenous infusion of biosynthetic human C-peptide (BHCP) ( $t=-60$ to $240 \mathrm{~min}$ ) mimicking meal stimulated Cpeptide secretion, with short-term oscillations (peak approximately every $12 \mathrm{~min}$ ) superimposed on the infusion profile. Plasma C-peptide was measured every $5 \mathrm{~min}$ ( $t=0$ to $240 \mathrm{~min}$ ). The BHCP infusion was reconstructed from C-peptide measurements using a population model of C-peptide kinetics and a deconvolution method. Bias, defined as the percentage difference between the total amount of calculated $\mathrm{BHCP}$ and the total amount of infused BHCP $(t=0$ to $240 \mathrm{~min})$, indicated that overall C-peptide secre-
\end{abstract}

tion can be measured with $14 \%$ [ $95 \%$ confidence interval (CI) -11 to $39 \%$ ] and $21 \%$ (95\% CI -3 to $45 \%$ ) accuracy in normal subjects and subjects with NIDDM respectively. Accuracy was not reduced by reducing the sampling frequency to every $30 \mathrm{~min}$. The root mean square error, measuring the average deviation between the infused and normalised calculated BHCP profiles, was also independent of the sampling frequency [mean $(95 \% \mathrm{CI}) 0.9$ (0.3 to 1.6) $\mathrm{pmol} / \mathrm{kg}$ per min in normal subjects; 1.0 (0.9 to 1.1) $\mathrm{pmol} / \mathrm{kg}$ per min in subjects with NIDDM]. Deconvolution employing a population model of C-peptide kinetics can be used to estimate postprandial total Cpeptide secretion with biases of $14 \%$ and $22 \%$ respectively in normal subjects and subjects with NIDDM. Plasma C-peptide samples need only be drawn every 30 minutes. [Diabetologia (1998) 41: 548-554]

Keywords Insulin secretion, C-peptide kinetics, normal subjects, type 2 diabetes, mathematical modelling.
Numerous studies have documented clearly that impaired insulin secretion contributes to the development of glucose intolerance and that a pronounced defect in insulin secretion is necessary for the full de-

Received: 19 May 1997 and in final revised form: 29 December 1997

Corresponding author: Dr. R. Hovorka, Metabolic Modelling Group, Centre for Measurement and Information in Medicine, City University, Northampton Square, London EC1V OHB, $\mathrm{UK}$

Abbreviations: NIDDM, non-insulin-dependent diabetes mellitus; BHCP, biosynthetic human C-peptide. velopment of non-insulin-dependent diabetes mellitus (NIDDM) [1]. Several methods, of varying complexity, are available to measure indices of insulin secretion in man. These include the hyperglycaemic clamp [2,3], the minimal model of C-peptide kinetics [4], and continuous infusion of glucose with model assessment [5]. However, a precise quantitative estimate of insulin secretion - that is, calculation of the instantaneous insulin secretion profile [6] - is often needed to characterise beta-cell function.

Insulin and C-peptide are secreted by the pancreas in a 1:1 molar ratio [7], but unlike insulin, C-peptide is not cleared by the liver and its kinetics are linear over a wide range of plasma concentrations [8]. This 
physiological feature forms the basis of a non-invasive method of estimating pre-hepatic insulin secretion using peripheral C-peptide measurements to calculate pancreatic C-peptide secretion [7].

Two methods are available for obtaining the description of C-peptide kinetics. The experimental method relies on the administration of a bolus injection of biosynthetic C-peptide (BHCP). Data analysis of the decay in plasma C-peptide then yields the parameters of C-peptide kinetics on an individual basis [9]. The second method benefits from analysis of Cpeptide decay curves from more than 200 subjects (including normal subjects and subjects with NIDDM), and uses a regression model to calculate population based (standard) values of parameters of Cpeptide [10]. The regression method obviates the need to perform an experiment involving administration of BHCP, but it risks introducing an error into the calculation because approximations are used.

Limited information is available about the extent of the error introduced by the population model. Nor is it known how and whether the sampling frequency affects the accuracy of the calculations. Short term oscillations (10-15 min between peaks) in Cpeptide secretion are known to be superimposed on the longer term patterns [11], and it is unclear whether and to what extent these affect the calculations. The present study addressed some of these issues. BHCP was infused to mimic meal-stimulated C-peptide secretion with short term oscillations present in the infused profile. The ISEC program [12], which implements the population model of C-peptide kinetics, was used to reconstruct the infused profile from plasma C-peptide concentrations measured every 5 min. All samples, and samples drawn every 15 and $30 \mathrm{~min}$, were analysed with ISEC to investigate the effect of the sampling schedule. Finally, studies were carried out in normal subjects and subjects with NIDDM to evaluate the effect of subject group.

\section{Subjects and method}

Subjects. Five healthy men [age range 28 to 43 years; body weight 68 to $84 \mathrm{~kg}$; BMI $\left(\mathrm{kg} / \mathrm{m}^{2}\right) 20.5$ to 24.5 ] and five men with NIDDM treated by diet alone (age 34 to 57 years; body weight 73 to $99 \mathrm{~kg}$; BMI 22.6 to 25.6 ) were studied after an overnight fast. They were admitted on the study day to the Diabetes Day Centre, St. Thomas' Hospital, London, UK, and fasted until the end of the study. Water was permitted as required. The study was approved by the Ethics Committee of West Lambeth Health Authority.

Experimental protocol. At about 8.00 a.m., a sampling cannula was inserted into the back of the hand. The hand was placed in a heating blanket to ensure arterialisation of the venous sample. The cannula was kept patent with a slow, continuous saline infusion. In the opposite arm, a cannula was inserted in a suitable vein for the variable infusion of biosynthetic human $\mathrm{C}$ peptide (BHCP) (Eli-Lilly, Ind., USA) and octreotide (soma- tostatin analogue, Sandoz Pharma, Basle, Switzerland). After a rest period of approximately $30 \mathrm{~min}$, two baseline samples were taken $5 \mathrm{~min}$ apart $(t=-100$ and $-95 \mathrm{~min})$. A constant infusion of octreotide $(1 \mu \mathrm{g} / \mathrm{min})$ was started and continued until the end of the experiment ( $t=-90$ to $240 \mathrm{~min}$ ). Blood samples were taken at $30 \mathrm{~min}$ intervals to measure plasma insulin and glucose concentrations. A variable infusion of $\mathrm{BHCP}$ began 30 min after the start of the octreotide infusion and continued until the end of the experiment ( $t=-60$ to $240 \mathrm{~min}$ ). Blood samples were taken at $5 \mathrm{~min}$ intervals, starting at time $t=-30 \mathrm{~min}$, and were analysed for C-peptide.

An independent assessment was carried out to evaluate the extent of residual C-peptide secretion during octreotide infusion. Before the study day, the subjects were given a $4 \mathrm{~h}$ octreotide infusion $(1 \mu \mathrm{g} / \mathrm{min})$ after an overnight fast, and blood samples were taken to determine the plasma C-peptide concentration. Data analysis of plasma C-peptide at the end of the infusion gave residual C-peptide concentrations (one concentration per subject). Using C-peptide population kinetics, the individual residual concentrations were converted into residual secretion rates (one constant secretion rate per subject), which were then subtracted from calculated rates of C-peptide appearance before visualisation and further analysis.

Variable BHCP infusion. The BHCP infusion was aimed to mimic meal-stimulated C-peptide secretion. It was constructed by (1) averaging and then smoothing (using cubic splines) Cpeptide secretion calculated by deconvolution [12] in 19 normal men after eating a meal (data not shown), and (2) by adding secretory pulses generated using a Poisson random process with a mean frequency of one pulse (alternative peak and trough) every $6 \mathrm{~min}$, to approximate the short-term oscillations in normal subjects [11]. The amplitude of the pulses was obtained by sampling a normal distribution with a mean of $20 \%$ of the value of the ambient secretion rate and a coefficient of variation (CV) of 50\% [13]. Peaks and troughs were interpolated linearly, providing data points at $1 \mathrm{~min}$ intervals. Finally, data points were smoothed with Savitzky-Golay 10 point moving window least squares quintic smoothing using two smoothing passes (Software Corporation, Durham, North Carolina, USA) to provide infusion rate as a piece-wise constant function with a 1-min step-size. The infusion was identical for all subjects when expressed in $\mathrm{pmol} / \mathrm{kg}$ per min, and was delivered using an IVAC 560R (IVAC, San Diego, California, USA) connected to a PC compatible computer and controlled by validated pump control software.

C-peptide, insulin, and glucose assay. Plasma C-peptide and plasma insulin concentrations were measured in duplicate by radioimmunoassay at SCL Biosciences Ltd. (Cambridge, UK). The intra-assay CV were $6 \%$ and $5 \%$, and detection limits were $12 \mathrm{pmol} / \mathrm{l}$ and $20 \mathrm{pmol} / \mathrm{l}$, respectively. Plasma glucose was determined on a Clandon Model 23 AM Glucose Analyser (Yellow Springs Instruments, Yellow Springs, Ohio USA; intra-assay CV $1 \%$ or less).

\section{Data analysis}

The ISEC program was used to reconstruct the infusion rates of BHCP [12]. In brief, ISEC implements a regularisation method of deconvolution constrained to non-negative values and uses a population model of C-peptide kinetics [10]. ISEC inputs the measured C-peptide plasma concentration, subject's age, weight, height, gender and classification (normal subjects, NIDDM) and produces as an output C-peptide secretion in the 
form of a piece-wise constant function. A 1-min step-size was adopted unless stated otherwise.

The regularisation component (smoothing factor) of the deconvolution analysis was chosen according to the discrepancy principle [14] to provide the $\mathrm{CV}$ of the residuals (differences between measured and estimated C-peptide concentrations) identical to the measurement error assumed to be at the level of $3.5 \%(\sim 6 / \sqrt{2}$ as the intra-assay CV of C-peptide assay was $6 \%$ and a mean of two duplicate measurements was subjected to the data analysis).

C-peptide secretion was calculated using samples collected during the period $t=0$ to $240 \mathrm{~min}$. The effect of sampling frequency on the accuracy of C-peptide was evaluated by subjecting C-peptide samples collected every (i) 5 min (all samples), (ii) $15 \mathrm{~min}$ (every third sample), and (iii) $30 \mathrm{~min}$ (every sixth sample) to the analysis.

In all calculations, ISEC was instructed to assume zero secretion before $t=-60 \mathrm{~min}$ (using basal option) and constant secretion between $t=-60$ and 0 min to fit exactly the C-peptide measurement at $t=0 \mathrm{~min}$. A break option was specified to allow for the presence of discontinuity at time $0 \mathrm{~min}$.

Measures of accuracy. The differences between the actual (pump delivery) and the estimated (ISEC calculation) infusion rates of BHCP (appearance rate) were assessed by calculating bias and the root means square (RMS) error. In detail:

$$
\text { Bias }=\frac{\mathrm{AUC}_{\mathrm{E}}-\mathrm{AUC}_{\mathrm{A}}}{\mathrm{AUC}_{\mathrm{A}}} \times 100 \%
$$

where $\mathrm{AUC}_{\mathrm{E}}$ is the area under the curve of the estimated rate, and $\mathrm{AUC}_{\mathrm{A}}$ is the area under the curve of the infused rate in the period $t=0-240 \mathrm{~min}$.

RMS (pmol/kg per min) was defined as

$\mathrm{RMS}=\sqrt{\int_{0}^{240} \frac{(r(t)-\varrho \hat{r}(t))^{2}}{240}} d t=\sqrt{\sum_{\mathrm{i}=1}^{240} \frac{\left(r_{\mathrm{i}}-\varrho \hat{r_{\mathrm{i}}}\right)^{2}}{240}}$

where $r(t)$ and $r_{\mathrm{i}}$ is the actual, $\hat{r}(t)$ and $\hat{r_{i}}$ is the estimated rate of BHCP infusion at time $t$ and $i$, respectively, and $\varrho$ is a normalisation constant. The equality between the integral and summation expression is due to both actual and estimated rates being piece-wise constant functions with a time-step of one minute. The summation expression was used to carry out the calculations. The normalisation constant was calculated as $\mathrm{Q}=\mathrm{AUC}_{\mathrm{A}} / \mathrm{AUC}_{\mathrm{E}}$ making RMS independent from bias.

Statistical analysis. Bias and RMS were analysed by ANOVA allowing for effects due to subject category (normal compared with NIDDM) and sampling frequency ( $5 \mathrm{~min}, 15 \mathrm{~min}$ and $30 \mathrm{~min}$ ) to be assessed. $95 \%$ confidence intervals (CI) were calculated to test whether bias was statistically different from zero. Statistical significance was declared at $p<0.05$. The values are represented as mean \pm SEM unless stated otherwise.

\section{Results}

Plasma glucose, C-peptide and insulin. In normal subjects, plasma glucose concentrations fell from a fasting level of $5.0 \pm 0.3 \mathrm{mmol} / \mathrm{l}$ to a minimum of $4.1 \pm 0.5 \mathrm{mmol} / \mathrm{l}(p<0.05$, paired t test, fasting level $)$ at $t=0 \mathrm{~min}$, and then increased to $5.8 \pm 0.5 \mathrm{mmol} / \mathrm{l}$ at the end of the study (NS, paired $t$ test, fasting level). In subjects with NIDDM, a similar decrease in glu-
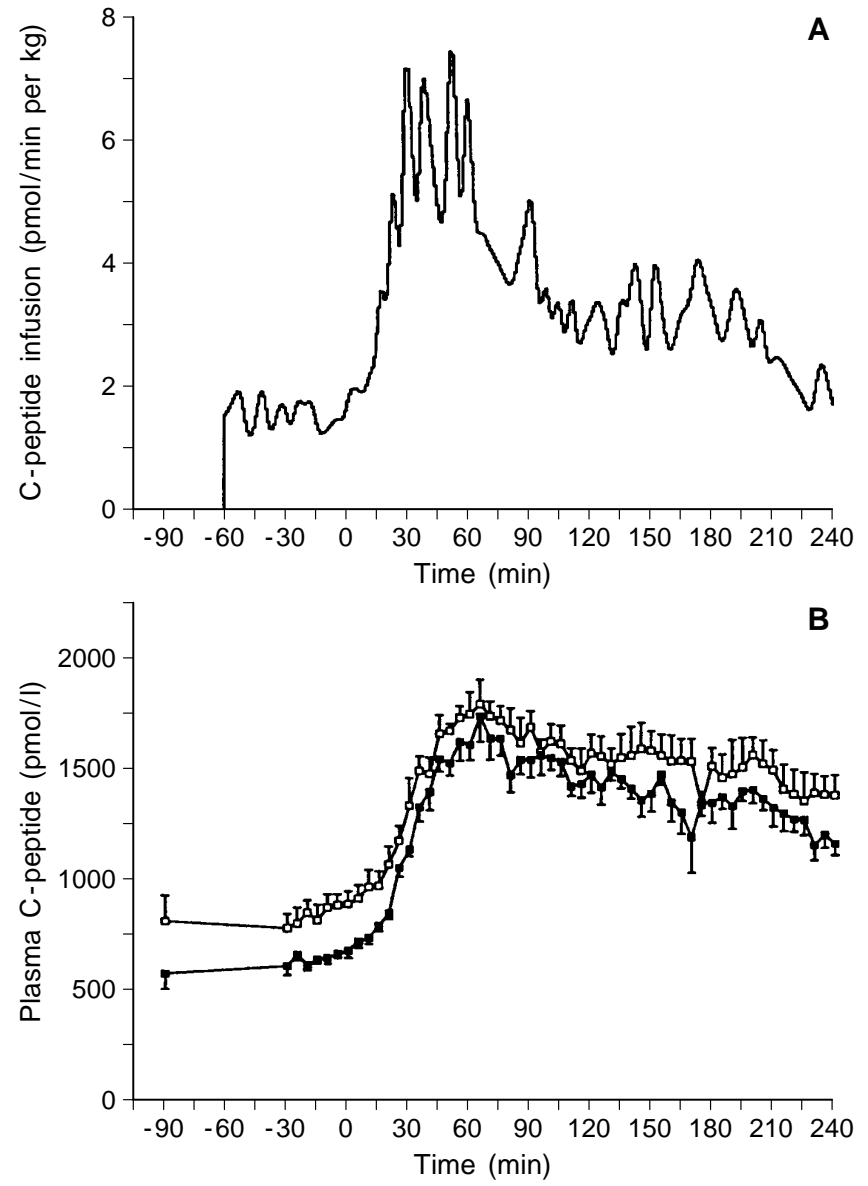

Fig.1. A variable infusion of $\mathrm{BHCP}(\mathbf{A})$ mimicking the mealstimulated C-peptide secretion, with superimposed short-term oscillations resulted in plasma C-peptide concentrations (B) in normal subjects $(\square)(n=5)$ and subjects with NIDDM ( $\square)$ $(n=5)$

cose was observed from a fasting level of $9.1 \pm 1.0 \mathrm{mmol} / 1$ to $8.3 \pm 0.9 \mathrm{mmol} / 1$ (NS) at $t=-10 \mathrm{~min}$ and then returned to a level of $8.7 \pm 0.7 \mathrm{mmol} / \mathrm{l}$ by the end of the study. Plasma insulin concentrations in normal subjects fell from a fasting value of $44.4 \pm 10.8 \mathrm{pmol} / \mathrm{l}$ to a level below the detection limit from $t=-30$ to $240 \mathrm{~min}$, and in subjects with NIDDM from $84.0 \pm 19.2 \mathrm{pmol} / \mathrm{l}$ to a mean of $\sim 30 \mathrm{pmol} / 1$ from $t=-60 \mathrm{~min}$ to $240 \mathrm{~min}$. Plasma C-peptide increased after the start of the BHCP infusion and peaked at $t=65 \mathrm{~min}(1742 \pm 117 \mathrm{pmol} / \mathrm{l}$ and $1796 \pm 112 \mathrm{pmol} / \mathrm{l}$ in normal subjects and subjects with NIDDM, respectively) and then fell to $1153 \pm 52 \mathrm{pmol} / \mathrm{l}$ and $1374 \pm 94 \mathrm{pmol} / \mathrm{l}$ respectively at $t=240 \mathrm{~min}$ (Fig. 1).

Analysis of plasma C-peptide concentrations during the independent assessment of residual C-peptide secretion indicated that octreotide did not fully suppress endogenous C-peptide secretion. Mean residual C-peptide concentrations of $224 \mathrm{pmol} / 1$ (range 0-616 $\mathrm{pmol} / \mathrm{l}$ ) and $365 \mathrm{pmol} / \mathrm{l}$ (range $235-479 \mathrm{pmol} / \mathrm{l}$ ) were found in normal subjects and subjects with NIDDM, 

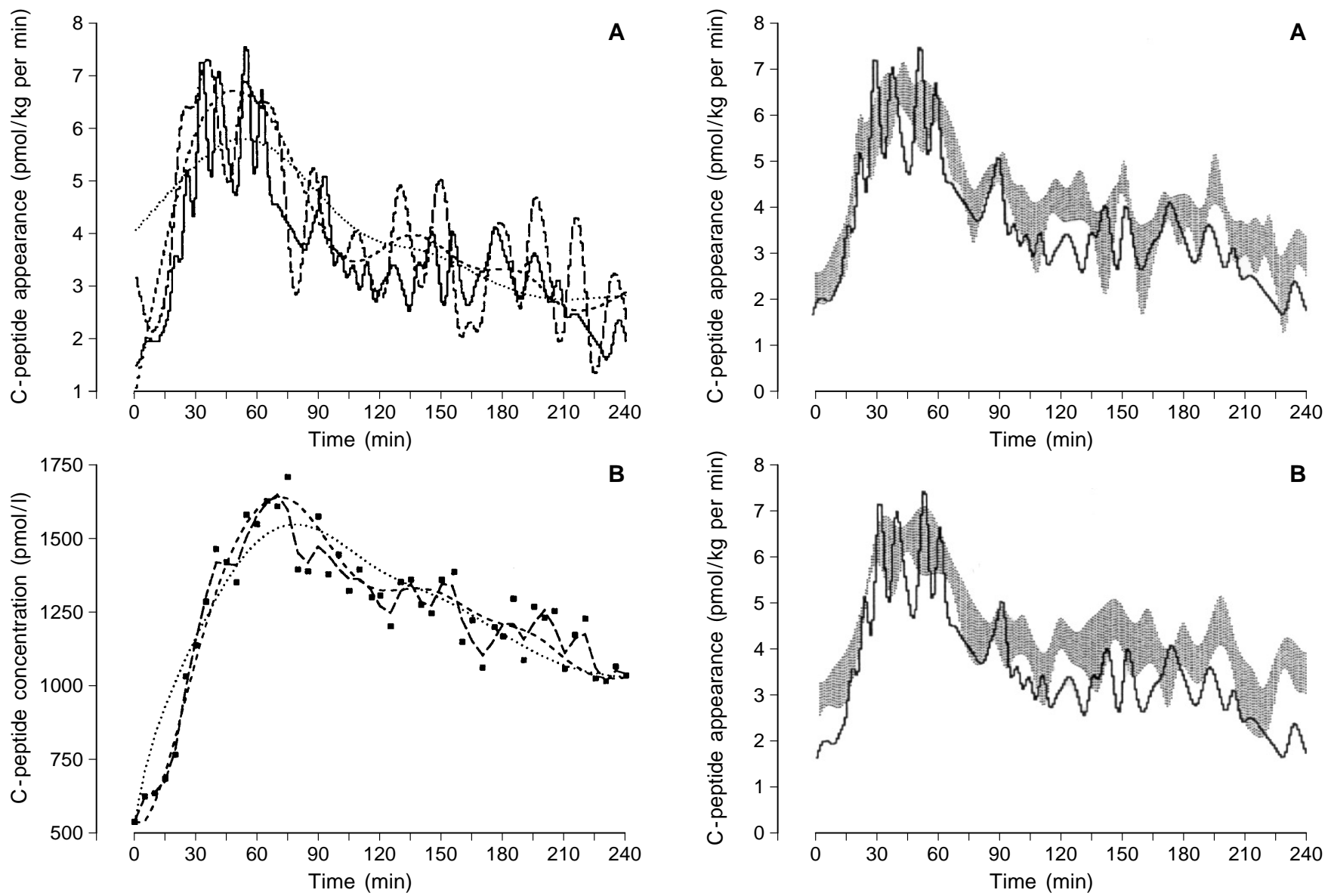

Fig. 2. Example analysis of data collected in a normal subject. (A) Infusion of BHCP (-) and calculated BHCP appearance rates using samples taken every $5 \mathrm{~min}(---)$, every $15 \mathrm{~min}$ (- - ), and every 30 min (.....). (B) Plasma C-peptide measurements ( $\square$ and fit to measurements using appearance rates shown in $\mathbf{A}$

respectively. Over the period $t=0$ to $240 \mathrm{~min}$, the mean residual secretions represented $16 \%$ (range $0-37 \%$ ) and $19 \%$ (range $13-27 \%$ ) of the BHCP infusion in the two subject groups, respectively.

C-peptide appearance. In all subjects, ISEC successfully calculated an estimate of the rate of BHCP infusion. An example of the results of the calculations for a single subject is shown in Fig. 2. The mean \pm SEM region of the estimated rate in normal subjects and subjects with NIDDM is given in Fig. 3. The total amount of BHCP infused in the period from $t=0$ to $240 \mathrm{~min}$ was $869 \mathrm{pmol} / \mathrm{kg}$. A positive bias (overestimation of BHCP infusion) was observed under a 5min sampling frequency at values of $14 \%$ (95\% CI -11 to $39 \%)$ and $21 \%(95 \% \mathrm{CI}-3$ to $45 \%)$ in normal subjects and subjects with NIDDM, respectively. After pooling the two subject groups, bias was statistically different from zero $(\mathrm{p}<0.05,95 \%$ CI 4 to $31 \%$ ). The sampling schedule and the subject category had no significant effects on bias (ANOVA). With

Fig. 3. Infusion of BHCP $(-)$ and the mean \pm SEM $(n=5)$ region (shaded) of calculated BHCP appearance in normal subjects (A) and subjects with NIDDM (B)

a 30-min sampling frequency, values for bias were $14 \%(95 \% \mathrm{CI}-11$ to $38 \%$ ) and $23 \%$ (95\% CI 0 to $45 \%$ ) in normal subjects and subjects with NIDDM, respectively.

With a 5-min sampling frequency, the values for root mean square error were $0.9 \mathrm{pmol} / \mathrm{kg}$ per min ( $95 \%$ CI 0.3 to $1.6 \mathrm{pmol} / \mathrm{kg}$ per min) in normal subjects and $1.0 \mathrm{pmol} / \mathrm{kg}$ per min (95\% CI 0.9 to 1.1 $\mathrm{pmol} / \mathrm{kg}$ per min) in subjects with NIDDM, representing about $25 \%$ and $30 \%$ respectively of the average infusion rate $(3.6 \mathrm{pmol} / \mathrm{kg}$ per $\mathrm{min})$. Again, no effects of subject category and the sampling schedule were seen on RMS (NS, ANOVA). With a 30-min sampling frequency, RMS was $0.9 \mathrm{pmol} / \mathrm{kg}$ per min ( $95 \%$ CI 0.8 to $0.9 \mathrm{pmol} / \mathrm{kg}$ per min) in normal subjects and $1.0 \mathrm{pmol} / \mathrm{kg}$ per min $(95 \%$ CI 0.8 to 1.3 $\mathrm{pmol} / \mathrm{kg}$ per min) in subjects with NIDDM.

Deconvolution analysis: effect of step-size and smoothing factor. Additional calculations were carried out using deconvolution with a 5-min step-size and a 5-min sampling frequency. The results were virtually identical to those obtained with a 1-min stepsize (data not shown). 

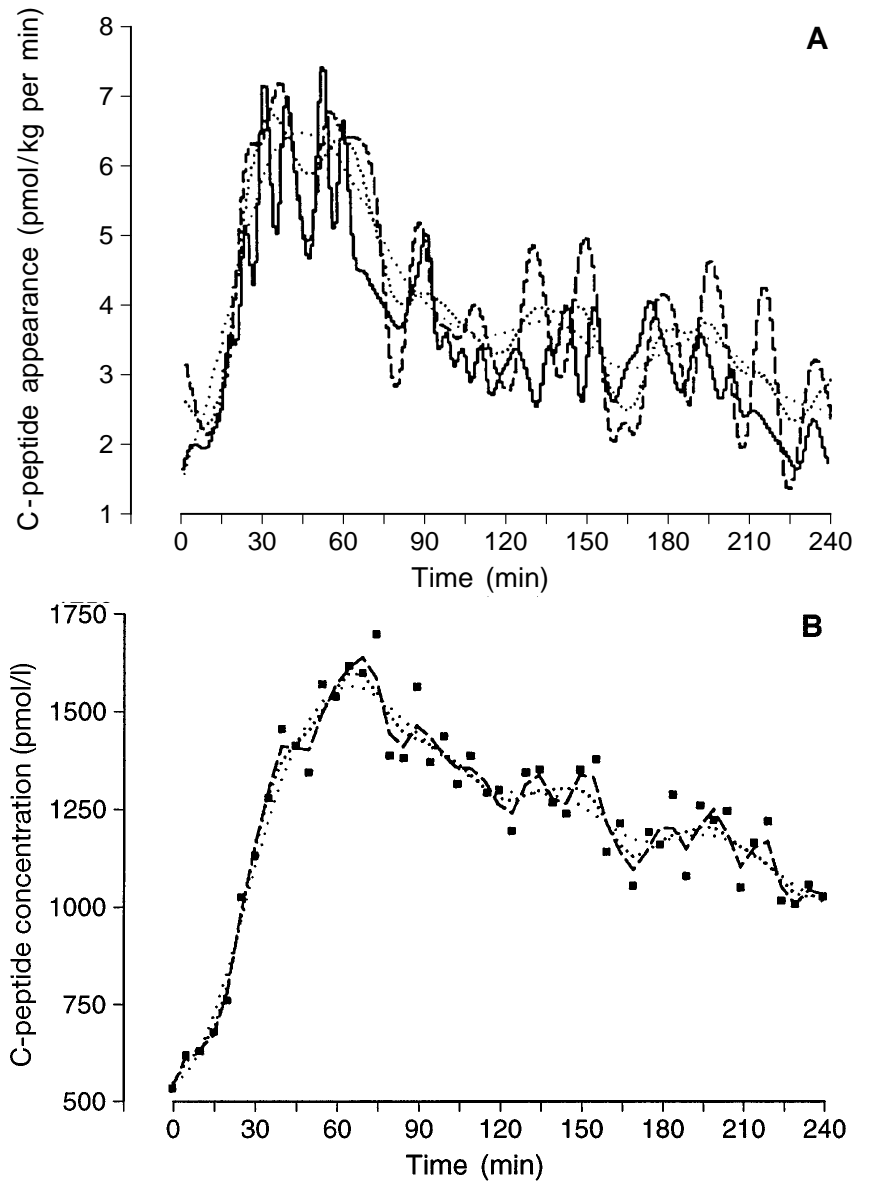

Fig. 4. Assessment of the effect of the smoothing factor. Example analysis in a normal subject using samples taken every 5 min. (A) The true (-) and calculated BHCP appearance rates using different smoothing factors that provide fit to the C-peptide measurements with average CV of 3.5 (- - default), 5 (- -), and 6\% (...). (B) Plasma C-peptide measurements (ם) and fit to measurements using appearance rates shown in $\mathbf{A}$

Another evaluation was carried out to assess the effect of smoothing factor (an assumed error in Cpeptide measurements expressed as $\mathrm{CV}$ ) on bias and RMS under a 5-min sampling frequency. An example of analysis in a normal subject using 3.5 (default), 5, and $6 \% \mathrm{CV}$ is shown in Fig. 4 . Bias did not change in either normal subjects (3\% CV $14 \pm 9 \%$ bias; $6 \%$ CV $13 \pm 9)$ or subjects with NIDDM (3\% CV $21 \pm 9$; $6 \%$ CV $20 \pm 9)$. RMS tended to decrease with increased $\mathrm{CV}$ in both normal subjects $(3 \% \mathrm{CV}$ $1.0 \pm 0.2 \mathrm{pmol} / \mathrm{kg}$ per min RMS; $6 \% \mathrm{CV} 0.8 \pm 0.1)$ and subjects with NIDDM (3\% CV $1.1 \pm 0.0 ; 6 \%$ CV $0.9 \pm 0.1)$.

\section{Discussion}

This study shows that meal-stimulated total C-peptide secretion can be calculated without an independent assessment of C-peptide kinetics and with accu- racies of $14 \%$ and approximately $22 \%$ in normal subjects and subjects with NIDDM, respectively. Sampling every $30 \mathrm{~min}$ is sufficient; increasing the sampling frequency to every 5 min does not improve the accuracy.

The benefits of avoiding individual assessment of C-peptide kinetics are clear. The experimental protocol is greatly simplified by avoiding the administration of a bolus injection of C-peptide. The infrequent sampling schedule provides further ethical, logistic and financial benefits.

The half-life of plasma C-peptide is rather long (around $30 \mathrm{~min}$ ), which may explain the absence of differences in bias at 5,15 and 30 min sampling intervals. Figs. 2 and 4 show another effect of the long half-life of plasma C-peptide. Larger fluctuations in $\mathrm{C}$-peptide appearance result in minor changes in plasma C-peptide concentrations. This makes the recovery of rapid pulsatility from plasma C-peptide difficult as gross underestimation or overestimation of the appearance rate provide very similar fits to the data and these inaccuracies are therefore difficult to eliminate. The assessment of the effect of the deconvolution step-size and regularisation (smoothing) factor suggests that this particular deconvolution method, in combination with the discrepancy principle, gives robust estimates of overall bias and RMS.

The study was designed to assess the accuracy of calculations of major secretion features of C-peptide in response to meal ingestion. No attempt was made to assess the accuracy of short term oscillations as this is most conveniently investigated during basal conditions or during a constant glucose infusion [15, 16]. The results of the present study do, however, indicate that 5-min sampling is not sufficient to recover short term oscillations. RMS was unaffected by the sampling schedule and remained virtually unchanged for the three sampling schedules.

RMS was also insensitive to the smoothing factor. This documents the difficulties associated with choosing the appropriate extent of smoothing. At a low level of smoothing, the appearance peaks and troughs are easily exaggerated, and at a high level, the true oscillatory pattern is not recovered (Fig. 4). It seems that individual rather than population choice of the smoothing factor (extent of the measurement error when using the discrepancy principle) is required. In the present study, no attempt was made to optimise the smoothing factor. Visual assessment indicated that the overall shape of the BHCP infusion was well reconstructed and it is concluded that RMS values were primarily a result of inability to reconstruct the superimposed short-term oscillatory patterns.

The extent to which the presence of non-negligible and potentially variable residual C-peptide secretion affected the calculation of bias and RMS is unclear. No relation was found between residual secretion and bias or RMS, but it is possible that the oscillatory 
character of residual C-peptide secretion contributed to the inability of the method to reconstruct simulated secretory pulses.

Polonsky et al. [8] showed that when individual estimates of the C-peptide kinetics are used bias values are $4 \%$ (range -12 to $22 \%$ ) and $5 \%$ ( -4 to $16 \%$ ) in normal subjects and subjects with insulin-dependent diabetes mellitus, respectively. Their study involved a variable infusion of $\mathrm{BHCP}$ in the form of a piecewise constant, physiological to high-physiological infusion rate with no short-term oscillations. These results, combined with those of the present study, show that bias was increased by $9 \%$ in normal subjects through the adoption of the population model of Cpeptide kinetics or short-term oscillations in the $\mathrm{BHCP}$ infusion rate, or both. Kjems et al. [17] indicated a mean bias of $-22 \%$ in normal subjects and subjects with NIDDM when mimicking an oral glucose tolerance test protocol and using an individual assessment of C-peptide kinetics. Sparacino et al. [18] investigated the accuracy of recovering the short term oscillations, but did not provide quantitative results.

The ease of use and benefits of the population model of C-peptide kinetics have been explored and confirmed, for example, by Toffolo et al. [4], in the context of estimating C-peptide secretion during an intravenous glucose tolerance test, and by Lewis et al. [19], when developing a new non-invasive method if measuring acute pancreatic insulin secretion. We concur with these findings, and acknowledge the value of the population model of C-peptide kinetics as a simple means of determining pre-hepatic insulin secretion.

Other approaches distinct from deconvolution have been developed to estimate C-peptide (and post-hepatic insulin) secretion. These are model-dependent methods that rely on a parameteric description of C-peptide secretion (either expressed as a cubic spline or a function of plasma glucose) $[4,20,21]$ and estimate, with a single exception [4], parameters of C-peptide kinetics from the data (no exogenous bolus of C-peptide was used in these studies). These methods require a good "signal" (increment in plasma C-peptide concentration) to discriminate between the secretion and removal of C-peptide. Kjems et al. [17] reported a bias of $-17 \%$ in normal subjects and subjects with NIDDM when using the combined model [20].

The infusion rate of BHCP in this study was constructed to mimic the meal stimulated C-peptide secretion rate seen in normal subjects. The short-term oscillations were added to the profile, thus providing a more physiological rate of appearance of C-peptide than the step-wise C-peptide infusion adopted by others $[7,8]$. The delivery of the infusion profile was only possible with the use of a computer-driven infusion pump as the infusion rate changed every minute and high precision was required.
In conclusion, we have shown that the use of deconvolution, employing a population model of $\mathrm{C}$ peptide kinetics, can estimate meal stimulated C-peptide secretion with biases of only $14 \%$ and $22 \%$ in normal subjects and patients with NIDDM, respectively. A 30 -min sampling schedule is sufficient. Increasing sampling frequency up to one sample every 5 min does not improve accuracy of these calculations. Care should be exercised when using the population model of C-peptide kinetics for subjects outside the validated categories.

Acknowledgements. Many thanks to Dr Alan Bye and Professor Ewart Carson for continuous support. Constructive and helpful suggestions by the referees are acknowledged.

\section{References}

1. DeFronzo RA (1992) Pathogenesis of type 2 (non-insulin dependent) diabetes mellitus: a balanced overview. Diabetologia 35: 389-397

2. Rudenski AS, Hosker JP, Burnett MA, Matthews DR, Turner RC (1988) The beta cell glucose stimulus-response curve in normal humans assessed by insulin and C-peptide secretion rates. Metabolism 37:526-534

3. DeFronzo RA, Tobin JD, Andres R (1979) Glucose clamp technique: A method for quantifying insulin secretion and resistance. Am J Physiol 237:E214-E223

4. Toffolo G, De Grandi F, Cobelli C (1995) Estimation of beta-cell sensitivity from intravenous glucose tolerance test C-peptide data: knowledge of the kinetics avoids errors in modeling the secretion. Diabetes 44:845-854

5. Levy JC, Rudenski A, Burnett M, Knight R, Matthews DR, Turner RC (1991) Simple empirical assessment of beta-cell function by a constant infusion of glucose test in normal and type 2 (non-insulin-dependent) diabetic subjects. Diabetologia 34:488-499

6. Polonsky KS, Given BD, Van Cauter E (1988) Twentyfour-hour profiles and pulsatile patterns of insulin secretion in normal and obese subjects. J Clin Invest 81:442-448

7. Polonsky KS, Frank BH, Pugh W et al. (1986) The limitations to and valid use of C-peptide as a marker of the secretion of insulin. Diabetes 35:379-386

8. Polonsky KS, Licinio-Paixao J, Given BD et al. (1986) Use of biosynthetic human C-peptide in the measurement of insulin secretion rates in normal volunteers and type I diabetic patients. J Clin Invest 77:98-105

9. Eaton RP, Allen RC, Schade DS, Erickson KM, Standefer J (1980) Prehepatic insulin production in man: kinetic analysis using peripheral connecting peptide behaviour. J Clin Endocrinol Metab 51:520-528

10. Van Cauter E, Mestrez F, Sturis J, Polonsky KS (1992) Estimation of insulin secretion rates from C-peptide levels: Comparison of individual and standard kinetic parameters for C-peptide clearance. Diabetes 41:368-377

11. Matthews DR, Lang DA, Burnett MA, Turner RC (1983) Control of pulsatile insulin secretion in man. Diabetologia 24:231-237

12. Hovorka R, Young MA, Soons PA (1996) ISEC: A program to calculate insulin secretion. Comput Methods Programs Biomed 50:253-264

13. Balks HJ, Schmidt A, Prank K, Hemmer F, von zur Muhlen A, Brabant G (1992) Temporal pattern of pancreatic insu- 
lin and C-peptide secretion and of plasma glucose levels after nutritional stimulation. J Clin Endocrinol Metab 75:1198-1203

14. Twomey S (1965) The application of numerical filtering to the solution of integral equations encountered in indirect sensing measurements. Journal of Franklin Institute 279:95-109

15. Sturis J, Van Cauter E, Blackman JD, Polonsky KS (1991) Entrainment of pulsatile insulin secretion by oscillatory glucose infusion. J Clin Invest 87:439-445

16. O'Rahilly SP, Turner RC, Matthews DR (1988) Impaired pulsatile secretion of insulin in relatives of patients with non-insulin-dependent diabetes. $\mathrm{N}$ Engl $\mathrm{J}$ Med 318:1225-1230

17. Kjems LL, Christiansen E, Volund A, Madsbad S (1996) Valid single-day method for calculating insulin-secretion in normal and NIDDM subjects. Diabetologia 39 (suppl 1):A160(Abstract)

18. Sparacino G, Sturis J, O’Meara NM, Byrne M, De Nicolao G, Polonsky KS, Cobelli C (1993) A deconvolution method to quantify rapid pulses in insulin secretion. In: Szeto AYJ, Rangayyan RM (eds) Proceedings of the 15th Annual International Conference of the IEEE Engineering in Medicine and Biology Society. IEEE, San Diego, pp 536-537

19. Lewis GF, Steiner G, Polonsky KS, Weller B, Zinman B (1994) A new method for comparing portal and peripheral venous insulin delivery in humans: tolbutamide versus insulin infusion. J Clin Endocrinol Metab 79:66-70

20. Volund A, Polonsky KS, Bergman RN (1987) Calculated pattern of intraportal insulin appearance without independent assessment of C-peptide kinetics. Diabetes 36: 1195-1202

21. Watanabe RM, Volund A, Roy S, Bergman RN (1989) Prehepatic beta-cell secretion during the intravenous glucose tolerance test in humans: application of a combined model of insulin and C-peptide kinetics. J Clin Endocrinol Metab 69:790-797 